\title{
SUMOYLATION OF THE NUCLEOCAPSID PROTEIN OF SEVERE ACUTE RESPIRATORY SYNDROME CORONAVIRUS BY INTERACTION WITH UBC9
}

\author{
Qisheng Li, Han Xiao, James P. Tam, and Ding X. Liu*
}

\section{INTRODUCTION}

Severe acute respiratory syndrome coronavirus (SARS-CoV) encodes a highly basic nucleocapsid $(\mathrm{N})$ protein of 422 amino acids. Similar to other coronavirus N proteins, SARS-CoV $\mathrm{N}$ protein is predicted to be phosphorylated and may contain nucleolar localization signals (NuLs), RNA binding domain, and regions responsible for selfassociation and homo-oligomerization. ${ }^{1-4}$ In this study, we identified Ubc9, a host protein involved in sumoylation, as a binding partner of the $\mathrm{N}$ protein in a yeast two-hybrid screen. This interaction was verified by GST pull-down assay, coimmunoprecipitation and colocalization of the two proteins in cells. Subsequent biochemical characterization studies demonstrate that SARS-CoV N protein is post-translationally modified by covalent attachment to the small ubiquitin-like modifier (SUMO). The major sumoylation site was mapped to the ${ }^{62}$ lysine residue of the $\mathrm{N}$ protein. Further expression and characterization of wild-type $\mathrm{N}$ protein and $\mathrm{K} 62 \mathrm{~A}$ mutant reveal that sumoylation of the $\mathrm{N}$ protein drastically promotes its homo-oligomerization. This is the first report showing that a coronavirus $\mathrm{N}$ protein undergoes post-translational modification by sumoylation and the functional implication of this modification in the formation of coronavirus ribouncleoprotein complex, virion assembly, and virus-host interactions.

\section{MATERIALS AND METHODS}

Transient expression of viral protein in HeLa cells: Constructs containing plasmid DNA under the control of a $\mathrm{T} 7$ promoter were transiently expressed in mammalian cells using the recombinant vaccinia virus (vTF7-3) system as described before. ${ }^{5}$ In this study, the transfection reagent used was Effectene (Qiagen).

\footnotetext{
*Nanyang Technological University, Singapore, 637551, and Institute of Molecular and Cell Biology, Proteos,
} Singapore, 1386731. 
Immunoprecipitation: Transiently transfected HeLa cells in 100-mm dishes were lysed in $1 \mathrm{ml}$ of lysis buffer with $0.5 \%$ protease inhibitor cocktail (Sigma). The lysates were centrifuged at $12,000 \mathrm{rpm}$ for $20 \mathrm{~min}$ at $4^{\circ} \mathrm{C}$. The supernatants were added with anti-His (Qiagen), anti-SUMO-1 (Zymed), or anti-Flag M2 (Stratagene) antibodies at $4^{\circ} \mathrm{C}$ for $2 \mathrm{~h}$. Protein-A agarose beads $(40 \mu \mathrm{l})(\mathrm{KPL})$ were added to the lysates and incubated with rolling for $1 \mathrm{~h}$ at $4{ }^{\circ} \mathrm{C}$. The beads were collected by centrifugation and washed three times with RIPA buffer. Proteins binding to the beads were eluted by adding $2 x$ SDS loading buffer and analyzed by Western blotting with anti-Flag antibody.

Expression of GST fusion protein and GST pull-down assay: The SARS-CoV N protein was cloned into pGEX-5X-1 and expressed as GST-N fusion protein in E. coli BL21 cells. Both GST-N and GST alone were purified by affinity chromatography using glutathione-Sepharose 4B (Amersham Pharmacia Biotech).

In vitro translation of Ubc9 was carried out using the T7-coupled rabbit reticulocyte lysate system in the presence of $\left[{ }^{35} \mathrm{~S}\right]$ methionine (Promega). For the binding assay, GST alone or GST-Ubc9 fusion proteins were prebound to glutathione-Sepharose beads. Five microliters of ${ }^{35} \mathrm{~S}$-labeled Ubc9 was then added, and incubation was continued for at least $2 \mathrm{~h}$. The beads were washed five times. Labeled proteins bound on the beads were analyzed by SDS-PAGE. Radiolabeled bands were visualized by autoradiography.

Indirect immunofluorescence: $\mathrm{SARS}-\mathrm{CoV} \mathrm{N}$ protein and Ubc9 were transiently expressed in HeLa cells. After rinsing with PBS, cells were fixed with 4\% paraformaldehyde for $15 \mathrm{~min}$ and permeabilized with $0.2 \%$ Triton $\mathrm{X}-100$, followed by incubation with specific antibodies diluted in fluorescence dilution buffer at room temperature for $2 \mathrm{~h}$. Cells were then washed with PBS and incubated with FITC- or TRITC-conjugated anti-rabbit or anti-mouse secondary antibodies (Dako) in fluorescence dilution buffer at $4^{\circ} \mathrm{C}$ for $1 \mathrm{~h}$ before mounting. All images were taken using a Zeiss LSM510 META laser scanning confocal microscope.

Construction of plasmids: Plasmid pcDNA3.1-N, which covers the SARS$\mathrm{CoV} \mathrm{N}$ sequence, was constructed by cloning an EcoRI/Not I digested PCR fragment into EcoRI/NotI digested pcDNA3.1(+). The PCR fragment was generated using primers (5'-CGGAATTCCGATGTCTGATAATG GACCC-') and (5'AATAAATAGCGGCCGCTGCCTGAGTTG AATC-3'). pFlag-N was created by cloning a Pst $/ E c o$ RI digested PCR fragment into Pst $/$ EcoR digested pKT0-Flag. Plasmid pGEX-N was made by cloning a BamHI- and EcoRI-digested PCR fragment into BamHI/EcoRI digested pGEX-5X-1 (Pharmacia). The K62A mutant was introduced by two rounds of PCR as described before. ${ }^{6}$ Human Ubc9 cDNA was inserted into pKT0Flag at the PstI/EcoRI cloning sites. Primers used were (5'-AACTGCAGC ATGTCGGGGATCGCCCTCAGC-3') and (5'-CGGAATTCCGTTATGAGGGCGCAAAC TTCTT-3'). SUMO-1 was amplified from a human cDNA library derived from HeLa cells by PCR with primers (5'-TATCGGATCCCATGTCTGACCAGGCAAAACC-3') and (5'-CGGATC CTCGAGCTAAACTGTTGAATGACCCCCCGT-3'). The PCR product was digested with $B a m \mathrm{HI}$ and $X h o \mathrm{I}$ and cloned into BamHI/XhoI digested pcDNA3.1 $(+)$ to generate pcDNA3.1-SUMO-1. All constructs were confirmed by automated nucleotide sequencing. 


\section{RESULTS}

\subsection{Identification of Ubc9 as an Interacting Protein of SARS-CoV N}

To identify host proteins that interact with the $\mathrm{N}$ protein, a yeast two-hybrid screen of a HeLa cDNA library was performed. We obtained 20 independent clones corresponding to Ubc9 among a total of 24 positive clones.

This interaction was first tested by GST pull-down assays. As shown in (Fig. 1a, lanes 3 and 4), ${ }^{35}$ S-labeled Ubc9 associated with GST-N fusion protein but not with GST alone.

In a subsequent coimmunoprecipitation experiment, an $18-\mathrm{kDa}$ band that represents the precipitated Ubc9 could only be detected in cells coexpressing His-tagged $\mathrm{N}$ and Flag-tagged Ubc9 (Fig. 1b, lanes 4-6).

Immunofluorescence analyses revealed that the $\mathrm{N}$ protein was distributed throughout the cytoplasm and the nucleolus (Fig. 1c). Ubc9 was present more abundantly in the nucleus than in the cytoplasm (Fig. 1c). A merged picture revealed that Ubc9 colocalized with the $\mathrm{N}$ protein in the cytoplasm and the nucleolus (Fig. 1c).

\subsection{Post-translational Modification of SARS-CoV N Protein by Sumoylation}

After confirming the interaction between the $\mathrm{N}$ protein and Ubc9, we then examined whether the $\mathrm{N}$ protein is modified by sumoylation. As can be seen in Fig. 2a, in addition to three major isoforms of $\mathrm{N}$ protein that were detected under all conditions, a protein species of approximately $65-\mathrm{kDa}$ was detected in cell lysates prepared with lysis buffer containing two isopeptidase inhibitors, iodoacetamide (IAA) and $N$-ethylmaleimide (NEM) (Fig. 2a, lanes 2, 3, and 5). Coexpression of N protein with SUMO-1 led to the

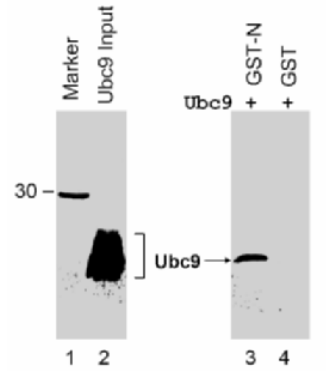

Figure 1a. GST pull-down assay.

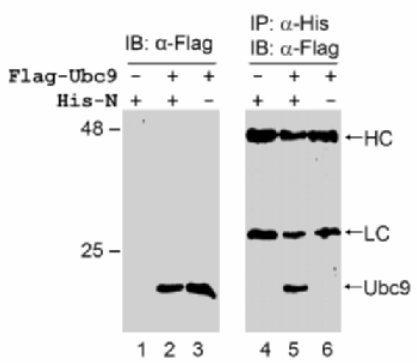

Figure. 1b. Co-IP assay.
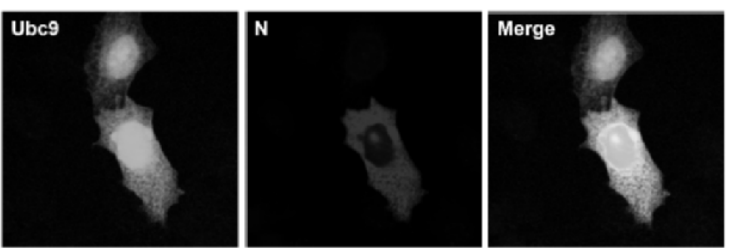

Figure 1c. Subcellular localization of $\mathrm{N}$ protein and Ubc9. 


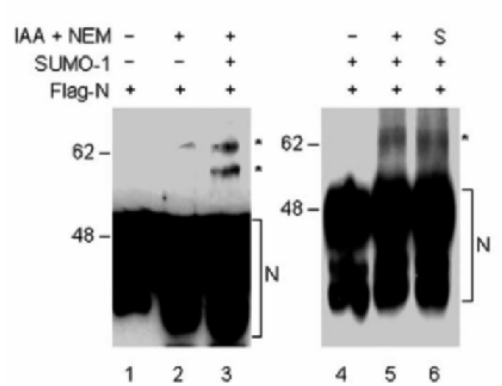

Figure 2a. Analysis of sumoylation of $\mathrm{N}$ protein by Western blot.

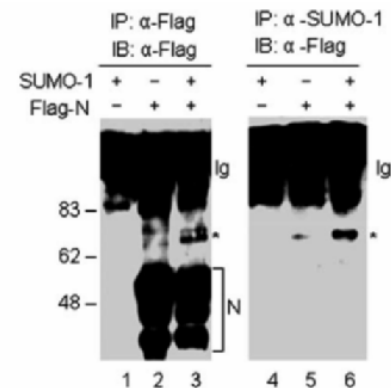

Figure 2b. Analysis of sumoylation of $\mathrm{N}$ protein by immunoprecipitation.

detection of significantly more $65-\mathrm{kDa}$ species (Fig. 2a, lane 3). The 65-kDa band was also detected when cells were lysed directly with preheated SDS loading buffer (Fig. 2a, lane 6).

Using immunoprecipitation, we confirmed that the $65-\mathrm{kDa}$ band represented the sumoylated $\mathrm{N}$ protein. Anti-Flag antibody precipitated the $65-\mathrm{kDa}$ species from cells transfected with pFlag-N (Fig. 2b, lanes 2 and 3). Analysis of the anti-SUMO-1 precipitates by Western blotting with anti-Flag antibody showed that only the $65-\mathrm{kDa}$ band was detected (Fig. 2b, lanes 5 and 6). Once again, coexpression of $\mathrm{N}$ protein with SUMO-1 greatly increased the detection of the $65 \mathrm{kDa}$ species (Fig. 2b, lanes 3 and 6).

\subsection{Mapping of the Sumoylation Site on SARS-CoV N Protein}

Analysis of the $\mathrm{N}$ protein sequence showed that one lysine residue at amino acid position 62 , K62, lies roughly within the consensus SUMO-1 modification sequence (GKEE). To determine whether this lysine was responsible for the modification of $\mathrm{N}$ protein by sumoylation, it was mutated to an Ala by site-directed mutagenesis. As shown in Fig. 3, similar amounts of the three isoforms of $\mathrm{N}$ protein were detected from cells transfected with either wild-type or mutant $\mathrm{N}$ constructs (Fig. 3, lanes 1 and 2). The $65-\mathrm{kDa}$ sumoylated band was detected from cells transfected with wild-type $\mathrm{N}$ protein only (Fig. 3, lane 1); no 65-kDa sumoylated form was detected from cells expressing the K62A mutant (Fig. 3, lane 2). These results demonstrated that the K62 residue is the major sumoylation site of $\mathrm{N}$ protein.

\subsection{Promotion of Homo-oligomerization of SARS-Cov N Protein by Sumoylation}

To study the effects of sumoylation on the homo-oligomerization of $\mathrm{N}$ protein, cells expressing N protein alone or together with SUMO-1 were analyzed. As shown in Fig. 4, Western blot analysis of cells expressing wild-type $\mathrm{N}$ protein showed the detection of the 65-kDa sumoylated band (Fig. 4A and $\mathrm{B}$, lanes 1 and 2). In addition, two bands of approximately 85 and $175 \mathrm{kDa}$ were detected (Fig. 4A and B, lanes 1 and 2). Based on their apparent molecular masses, they may represent dimers and tetramers, respectively, of the $\mathrm{N}$ protein.

Coexpression of wild-type $\mathrm{N}$ protein with SUMO-1 dramatically increased the detection of the $65-\mathrm{kDa}$ sumoylated band and the $85-\mathrm{kDa} / 175-\mathrm{kDa}$ oligomers (Fig. 4B, lane 3 and), Co-expression of the K62A mutant with SUMO-1, once again, showed no detection of the $65-\mathrm{kDa}$ sumoylated $\mathrm{N}$ protein (Fig. 4B, lane 5). Interestingly, only a trace amount of the $85-\mathrm{kDa}$ and $175-\mathrm{kDa}$ species was detected (Figure $4 \mathrm{~B}$, lane 5 ). These results suggest that abolishment of sumoylation of the $\mathrm{N}$ protein by mutating the $\mathrm{k} 62$ sumoylation site significantly decreases homo-oligomerization of the protein. 


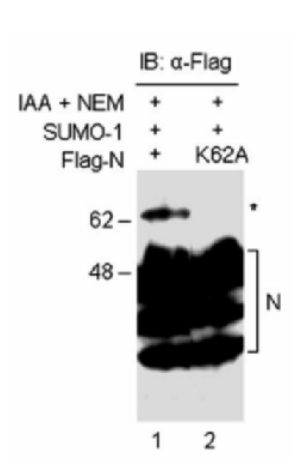

Figure 3. Mapping the major sumoylation site on $\mathrm{N}$ protein.
A

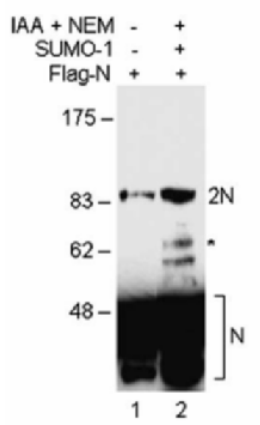

B

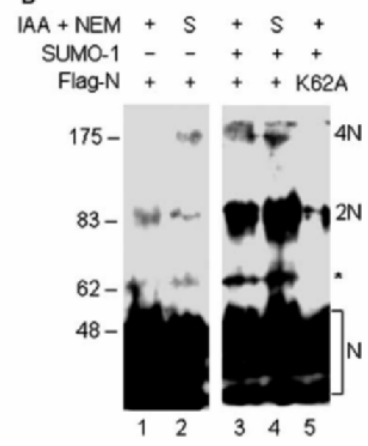

Figure 4. Analysis of the homo-oligomerization of SARS-CoV N protein.

\section{DISCUSSION AND CONCLUSION}

In this study, we identified Ubc9 as a host protein that interacts specifically with SARS-CoV $\mathrm{N}$ protein. This interaction was verified both in vivo and in vitro. Furthermore, we showed that, in addition to phosphorylation, the $\mathrm{N}$ protein was modified by covalent attachment of SUMO to its lysine 62 residue. Evidence provided demonstrated that sumoylation may promote homo-oligomerization of the protein.

SUMO-1 conjugation of a protein (sumoylation) is a highly regulated process in all eukaryotes, involved in diverse regulatory events such as nuclear transport, transcriptional regulation, chromosome segregation, and cell-cycle control. ${ }^{7-1}$

Recent studies have shown that the C-terminal one-third region is essential for selfassociation and multimerization of the SARS-CoV N protein., ${ }^{412}$ Data reported in this study demonstrate that sumoylation of the SARS-CoV N protein dramatically enhances the homo-oligomerization of the protein. Promotion of oligomerization of protein by sumoylation has been speculated for a pathogenic protein, Huntingtin. ${ }^{13}$ Because selfassociation and homo-oligomerization of $\mathrm{N}$ protein are essential for the assembly of nucleocapsid core, it suggests that sumoylation would play an important role in the SARS-CoV replication cycles. Systematic testing of this possibility would rely on the availability of an infectious cloning system, as developed by Yount et al. ${ }^{14}$

The failure to detect the sumoylated dimer in this study is unexpected, considering that sumoylation was shown to promote dimerization of the $\mathrm{N}$ protein. Two possibilities have been considered. First, sumoylation is a highly reversible process. The current data showed that only a small proportion of the $\mathrm{N}$ protein was dimerized compared with the monomers, and a certain proportion of the sumoylated dimer may be reversed during sample preparation and detection. The second possibility is that the sumoylated $\mathrm{N}$ protein may be not directly involved in the formation of dimmers and other oligomers. Instead, it may target the $\mathrm{N}$ protein to different cellular compartments and facilitate the oligomerization of the $\mathrm{N}$ protein. Further studies are required to address these possibilities. 
Site-directed mutagenesis studies mapped the ${ }^{62}$ lysine residue as a major site for covalent attachment of SUMO to the protein. We do not know whether other minor sumoylation sites may exist in the SARS-CoV N protein. Potential sumoylation at these minor positions would compensate the effect of K62A mutation. Sumoylation of protein at multiple sites was recently reported for several viral and host proteins. As the SARS$\mathrm{CoV} \mathrm{N}$ protein contains a total of 27 lysine residues and no any other lysine residue is located in a consensus sequence context for sumoylation, it would be difficult to further define these sites, if any, by a conventional mutagenesis approach.

\section{REFERENCES}

1. Lai, M. M., and Cavanagh, D., The molecular biology of coronaviruses, Adv. Virus Res. 48:1-100 (1997).

2. Wurm, T., Chen, H., Britton, P., Brooks, G., and Hiscox, J. A., Localization to the nucleolus is a common feature of coronavirus nucleoproteins and the protein may disrupt host cell division, J. Virol. 75:9345-9356 (2001).

3. Huang, Q., Yu, L., et al., Structure of the N-terminal RNA-binding domain of the SARS CoV nucleocapsid protein, Biochemistry 43:6059-6063 (2004).

4. Yu, I. M., Gustafson, C. L. T., et al., Recombinant SARS coronavirus nucleocapsid protein forms a dimmer through its C-terminal domain, J. Biol. Chem. 280:23280-23286 (2005).

5. Liu, D. X., Cavanagh, P. G., and Inglis, S. C., A polycistronic mRNA specified by the coronavirus infectious bronchitis virus, Virology 184:531-544 (1991).

6. Liu, D. X., Xu, H. Y., and Brown, T. D. K., Proteolytic processing of the coronavirus infectious bronchitis virus 1a Polyprotein: identification of a 10-kilodalton polypeptide and determination of its cleavage sites, $J$. Virol. 71:1814-1820 (1997).

7. Muller, S., Hoege, C., Pyrowolakis, G., and Jentsch, S., SUMO, ubiquitin's mysterious cousin, Nat. Rev. Mol. Cell Biol. 2:202-210 (2001).

8. Seeler, J. S., and Dejean, A., Nuclear and unclear functions of SUMO, Nat. Rev. Mol. Cell Biol. 4:690-699 (2003).

9. Pichler, A., and Melchior, F., Ubiquitin-related modifier SUMO1 and nucleocytoplasmic transport, Traffic 3:381-387 (2002).

10. Verger, A., Perdomo, J., and Crossley, M., Modification with SUMO. A role in transcriptional regulation, EMBO Rep. 4:137-142 (2003).

11. Wilson, V. G., and Rangasamy, D., Viral interaction with the host cell sumoylation system, Virus Res. 81:17-27 (2001)

12. Surjit, M., Liu, B., Kumar, P., Chow, V. T. K., and La, S. K., The nucleocapsid protein of the SARS coronavirus is capable of self-association through a C-terminal 209 amino acid interaction domain, Biochem. Biophys. Res. Commun. 317:1030-1036 (2004)

13. Steffan, J. S., Agrawal, N., et al., SUMO modification of Huntingtin and Huntington's disease pathology, Science 304:100-104 (2004).

14. Yount, B., Curtis, K. M., et al., Reverse genetics with a full-length infectious cDNA of severe acute respiratory syndrome coronavirus, Proc. Natl. Acad. Sci. USA 100:12995-13000 (2003). 